\title{
“VOCÊS ESTÃO SOZINHAS?” A RESPOSTA ESTÁ NA PERGUNTA
}

\author{
"Are you two alone?" The answer is in the question
}

\author{
Eliane Santos da Silva \\ https://orcid.org/0000-0001-7011-3623 \\ Universidade Federal de Santa Catarina, Programa de Pós-Graduação em Literatura, SC, \\ Brasil. 88040-900 - ppglitufsc@gmail.com

\section{Rosana Cássia dos Santos} \\ https://orcid.org/0000-0002-3950-8157 \\ Universidade Federal de Santa Catarina, Departamento de Língua e Literatura Vernáculas, \\ SC, Brasil.88040-900-1lv@contato.ufsc.br
}

Resumo: As narrativas onde apareciam personagens lésbicas na literatura brasileira, até recentemente, eram quase que exclusivamente de autoria de escritores e na maioria delas traziam estereótipos que reproduziam os elementos do heterocentrismo e androcentrismo fazendo com que a manutenção de uma imagem estereotipada da lésbica se perpetuasse no ambiente social. Este texto é resultado de uma leitura e posterior análise do conto "Duas mulheres sozinhas" de Diedra Roiz (2017) que faz parte da coletânea de contos Incontadas Aquelas que não podem falar dizendo o que não deve ser dito lançada pela Editora Vira Letra em 2017, com o objetivo de localizar no decorrer da narrativa as ocorrências evidenciando os conceitos de performatividade de Judith Butler (2013a), tecnologia de gênero de Teresa de Lauretis (1994), heteronormatividade compulsória de Adrienne Rich (2010) e epistemologia do armário de Eve Kosofsky Sedgwick (2007) e de como estas ocorrências influenciam na experiência individual de cada personagem do conto fazendo um paralelo do desenrolar das cenas com as teorias apresentadas como corpus teórico.

Palavras-chave: Heterocentrismo. Heteronormatividade. Lésbicas. Mulheres.

Abstract: The narratives where lesbian characters appeared in Brazilian literature, until recently, were almost exclusively authored by male writers, and most of them featured stereotypes that reproduced the elements of heterocentrism and androcentrism, keeping the stereotypical image of the lesbian perpetuated in the social environment. This text results from a reading and subsequent analysis of the short story "Two women alone" by Diedra Roiz (2017) - that is part of the short stories' collection named "Incontadas - Those who cannot speak saying what should not be said" published by Editora Vira Letra (Franca/SP) in 2017 -, aiming to locate, during the narrative, the occurrences evidencing the concepts of, Judith Butler's Performativity (2013), Teresa de Lauretis's Gender Technology (1994), Adrienne Rich's Compulsory Heteronormativity (2010) and Sedgwick's Closet's Epistemology (2007) and how

Esta obra está licenciada sob uma Creative Commons - Atribuição 4.0 
these occurrences influence the individual experience of each character of the short story making a parallel between the unfolding of the scenes and the theories presented as theoretical corpus.

Keywords: Heterocentrism. Heteronormativity. Lesbians. Women.

\section{Introdução}

Nossa trajetória na literatura, primeiramente, como leitora que teve uma formação escolar nas décadas de 80 e 90 cujos referenciais foram os grandes cânones da literatura brasileira e, também, sem a oportunidade de refletir no âmbito curricular acerca das representações que se apresentavam foram necessários alguns atravessamentos que permitiram outras reflexões. A falta de representatividade e de representação de mulheres em sua diversidade e pluralidade nas narrativas ficcionais incomodava e causava certo estranhamento sobre os motivos deste silenciamento, a busca por estas respostas nos mostrou um percurso que culminou na aventura da autoria. Recentemente, com o advento da internet encontramos um espaço de fala onde nossa voz é ouvida, embora não reverbere no circuito da grande mídia, em que o domínio ainda é do sujeito masculino, branco e heterossexual, já percebemos aí uma possibilidade de fissura no sistema, uma vez que acreditamos que a arte, no caso a literatura, é um dos principais caminhos para as transformações do pensamento.

Este trabalho tem seu ponto de partida em um movimento de (re)configuração na literatura brasileira que começa na segunda metade do século XX com algumas publicações importantes e se consolida no início do século XXI, tanto em termos quantitativos quanto qualitativos no que diz respeito à representação e representatividade das mulheres na literatura, embora muito aquém em termos absolutos conforme demonstra Regina Dalcastagnè (2010). Porém, as mudanças provenientes do advento da internet e da proliferação de blogs e sites trouxeram à cena novas escritoras e personagens que rompem com determinadas regras e estereótipos presentes na produção nacional. As narrativas com personagens lésbicas com enredos trazendo o cotidiano, os conflitos, as vivências e todo o contexto social, econômico e político muitas vezes distante do destino falogocêntrico ${ }^{1}$ vem marcando veementemente essa nova experiência literária. Muitas escritoras circulam em locais, ainda, distantes da grande mídia que define seus cânones, mas algumas conseguem romper e encontram algumas fissuras nesse sistema começando a aparecer em um contexto mais amplo. Vemos o surgimento de escritoras declaradamente lésbicas que assumem certo protagonismo na literatura nacional. Para citar algumas, como Natália Polesso que ganhou o prêmio Jabuti em 2016, com o livro de contos Amora, Tatiana Nascimento com sua poesia questionadora da heteronormatividade, Cidinha da Silva com crônicas provocativas ao senso-comum e representando a negritude em cada linha e Diedra Roiz, escritora que inicia sua trajetória literária na internet e que atualmente conta com 20 livros publicados e diversas participações em coletâneas de contos. Um deles, objeto deste trabalho. E muitas outras escritoras, inclusive a própria experiência pessoal e lugar de fala como

\footnotetext{
${ }^{1}$ Neologismo cunhado por Jacques Derrida (falocentrismo + logocentrismo) para produzir uma crítica às teses de Jacques Lacan no célebre seminário sobre o conto de Edgar Alan Poe, "The Purloined Letter", que Derrida considera pecar por falogocentrismo (SPIVAK, 1998).
}

Anu. Lit., Florianópolis, v. 25, n. 1, p. 77-86, 2020. ISSNe 2175-7917 
escritora enquanto acadêmica.

\section{"Duas mulheres sozinhas" e outras tantas}

Neste texto, o objetivo é localizar no enredo do conto escolhido os conceitos de performatividade de Judith Butler (2013a), Tecnologia de gênero de Teresa de Lauretis (1994), heteronormatividade compulsória de Adrienne Rich (2010) e epistemologia do armário de Eve Kosofsky Sedgwick (2007) e de como tais conceitos na prática aparecem na experiência individual de cada personagem do conto "Duas mulheres sozinhas" de Diedra Roiz (2017). Não há aqui a intenção de nos aprofundarmos nas teorias uma vez que estas leituras fazem parte de percurso em desenvolvimento e em andamento para uma pesquisa maior.

O texto de Diedra Roiz (2017) é todo em terceira pessoa, a narração é onisciente e temos as vozes interiores permitindo acompanhar o fluxo de consciência das personagens. O título, "Duas mulheres sozinhas" por si só já carrega inúmeras interpretações que irão aparecendo no decorrer da narração.

Comecemos, então, na primeira linha, onde a narradora faz-nos sentirmos sentadas na mesa ao lado na expectativa do desenrolar do ato: - "Vocês estão sozinhas "? (ROIZ, 2017, p. $73)$.

Pergunta o sujeito a duas mulheres. Simples assim. A cena poderia ser num bar final da tarde, numa sorveteria ou num café. E a resposta poderia ser: - Sim, estamos. E da mesma forma que começou, terminaria. Simples assim. Olharíamos a cena com pouco interesse e nos atentaríamos novamente à nossa rotina.

Mas, vamos tornar mais complexo o ato antes da resposta derradeira das duas mulheres. Pensemos no interlocutor dotado de um poder há muito tempo legitimado por uma sociedade androcêntrica e que por meio de gestos e signos reforçam a construção do corpo masculino e do outro lado duas mulheres "sozinhas", reforçando o imaginário da disponibilidade.

Com essa pergunta começa o conto de Diedra Roiz (2017), cuja resposta só é revelada no final e que acompanhamos como vai se construindo aos poucos na mente das duas protagonistas, Marcela e Vivi, diante de um interlocutor claramente seguro e acreditando que pode e deve se colocar como o sujeito ausente na cena, ignorando o fato das duas protagonistas serem lésbicas. A autora chama atenção de forma subjetiva neste conto para uma situação costumeira no universo das lésbicas, que muitas vezes são interpeladas por estarem “disponíveis", na visão do outro, ou muitas vezes são agredidas por estereotiparem condutas que não condizem com o sistema sexo-gênero, conforme Lauretis (1994), o sistema sexo-gênero determina que os papéis do masculino e feminino devem ser de acordo com o sexo e que começam a ser incorporados muito cedo, sendo previamente marcados pelas diversas tecnologias sexuais ao longo da história ocidental:

Embora a criança tenha um sexo 'natural', é só quando ela se torna [...] menino ou menina que adquire um gênero. [...] então, [...] gênero não é sexo, uma condição natural, e sim a representação de cada indivíduo em termos de uma relação social preexistente ao próprio indivíduo e predicada sobre a posição 
'conceitual' e rígida (estrutural) dos dois sexos biológicos. (LAURETIS, 1994, p. 211).

Portanto, o sistema sexo-gênero é um sistema de representação que, ao atribuir significado, condiciona os sujeitos a pré-determinados papéis sociais. Assim, a pergunta que dá razão ao conto e à nossa reflexão se justifica em um contexto no qual os gêneros aparecem marcadamente situados e justificados pela heteronormatividade, onde o sujeito masculino se vê em situação de poder em relação ao feminino.

Para compreendermos o momento descrito pela narradora precisamos contextualizar a situação vivenciada pelas protagonistas em virtude de alguns elementos presentes no texto como a linguagem atribuída às personagens, a descrição do ambiente e as situações vivenciadas. Pode-se concluir, antecipadamente, que estão em um bar, provavelmente nas primeiras décadas do século XXI, provavelmente em alguma grande cidade brasileira. $\mathrm{O}$ nome das personagens Marcela e Vivi, bem como o pequeno fragmento no fluxo de pensamento de Vivi: “[...] era assumida, nunca tinha escondido o que sentia por Marcela, nem que eram casadas [...]" (ROIZ, 2017, p. 75) nos remete ao romance publicado pela autora em 2008, Amor a qualquer preço ${ }^{2}$, o que nos leva a pensar que esse conto poderia ser uma derivagem ou uma história derivada (spin-off) do referido livro.

Retornando a pergunta inicial e que introduz Marcela e Vivi a uma sequência de pensamentos e posicionamentos diante da indagação repleta de significados do sujeito que por ser homem heterossexual coloca-se na posição de elemento faltante naquele quadro, pois “"[...] mesmo quando localizada no corpo da mulher [...], a sexualidade é percebida como um atributo ou uma propriedade do masculino.” (LAURETIS, 1994, p. 222). O silêncio das personagens diante da indagação é interpretado erroneamente, pois a narração demonstra claramente haver entre elas olhares apaixonados que foram ignorados fazendo com que uma segunda pergunta que vem logo a seguir demonstre o local de fala do sujeito: “- Posso me sentar?” (ROIZ, 2017, p. 73).

A situação vivenciada pelas personagens está enraizada na matriz heterossexual que limita os corpos a uma diferença sexual e com isso carrega consigo toda uma instituição normativa, uma vez que tais normas não são comprometidas pelo discurso dos corpos não ocorre também o conflito com a sexualidade. Dando assim, a falsa noção de estabilidade por meio das dicotomias homem/mulher, masculino/feminino. (BUTLER, 2013b).

Para a personagem Marcela "não era a primeira vez nem seria a última" (ROIZ, 2017, p. 73), mas representava a violação da sua identidade, como se não the fosse permitido vivê-la plenamente: "A prova concreta de tudo que o simples fato de serem um casal de mulheres num mundo injusto e cruel lhes roubava. Sabia que se uma delas fosse homem, o outro jamais teria se aproximado." (ROIZ, 2017, p. 74).

Percebe-se aqui a experiência de vida da personagem e certa aceitação constrangida e justificada da ação do sujeito, pois conforme propõem Rich (2010), a heterossexualidade

\footnotetext{
${ }^{2} \mathrm{O}$ romance Amor a qualquer preço, foi publicado pela primeira vez na internet em 2008 e após revisão e atualizações foi publicado pela Editora Vira Letra em 2016.
} 
compulsória age como uma instituição política que retira o poder das mulheres e as coloca em situação de opressão diante das regras determinadas. Marcela deixa claro nesse pensamento as violências simbólicas e não simbólicas que estavam submetidas e que operam de forma coercitiva diante de regras e padrões falocêntricos.

$\mathrm{Na}$ continuidade do pensamento de Marcela, temos a elucubração de Vivi que pensa que se fosse uma lésbica com atributos e estereótipos que não marcassem a feminilidade evitaria tais situações:

Vivi também estava cansada. Exausta de uma vida inteira sendo incomodada [...] ofensivamente sendo assediada apenas por não atender aos estereótipos que talvez fizessem com que esse e outros galanteadores inconvenientes e indesejáveis lhe deixassem em paz e que a impedissem de ouvir uma vez mais: "você não parece nem um pouco", como se fosse o maior dos elogios, algo a ser comemorado. (ROIZ, 2017, p. 74).

A personagem, aqui, nos revela mais naquilo que foi silenciado do que no revelado. Ao se colocar na situação da lésbica que performatiza o feminino e é alvo de "galanteadores", faz emergir o estigma da lésbica que é aceita e circula tranquilamente atendendo os padrões permitidos, pois não fere o binarismo de gênero, se molda ao padrão heteronormativo no que se refere a performance, sendo que se houvesse a desestabilização deste dicotômico homem/mulher e masculino/feminino traria, também, um conflito com a sexualidade, na compreensão da personagem afastando situações que ela vivencia. E, demonstrando, também, incômodo com aquilo que para alguns seria um elogio, ela deixa claro que o fato de "[...] não parece nenhum um pouco" também a incomoda, colocando-se em um local que ela não consegue definir. As marcas que fundamentam cada gênero estão enraizadas e tornam-se naturalizadas legitimando o binarismo masculino/feminino denotando a performatividade correspondente e esperada (BUTLER, 2013a).

A performatividade não é assim um ato singular, pois ela é sempre uma reiteração de uma norma ou conjunto de normas. E, na medida em que ela adquire o status de ato no presente, ela oculta ou dissimula as convenções das quais ela é uma repetição. (BUTLER, 2013a, p. 13).

E a partir desta configuração estabelecida esta reprodução ou repetições conforme afirma Butler (2013a) ocorre em todas as instituições do social sem que ocorram fissuras externas. E, ao fazermos a relação com a heteronormatividade temos justificada a ação do sujeito masculino no conto.

Para pensarmos em como se reproduzem estes estereótipos, temos no exemplo da história da literatura nacional o fato de que até recentemente a personagem lésbica que era narrada e descrita por escritores masculinos traziam uma fetichização, conforme a amostra apresentada por Claudiana Gois dos Santos (2018) em sua dissertação:

fato que indica uma reinante estereotipia sobre as protagonistas homoafetivas e seus relacionamentos, além disso, o erotismo entre duas mulheres aparece fadado a servir ao masculino, tanto que, muitas vezes, advém desse mesmo 
masculino a dúvida sobre a existência autônoma dos relacionamentos entre mulheres. Perceber essa particularidade é importante para pensar a ideia da heteronormatividade presente [...] inclusive em obras contemporâneas. (SANTOS, 2018, p. 29).

Retornando a personagem Vivi, ela nos informa também que ao se tornar mais "pintosa" estaria afastando o indesejável. O termo "pintosa" no universo das lésbicas tem o significado de denotar as características que a identifiquem como lésbica, deixando claro que, na opinião dela, existe uma performance particular sem levar em consideração, neste caso, a pluralidade do universo lésbico. Entendemos, aqui, que essa performance se configura pela forma como a personagem da lésbica estereotipada aparece nos diversos meios midiáticos e na literatura. Para Butler (2013a) o gênero não é algo natural, não existe relação entre corpo e gênero, sendo que um corpo designado como fêmea pode não exibir os traços considerados femininos, tampouco tem relação com o desejo, permitindo com isso muitas configurações.

Ao não nos afastarmos do binarismo de gênero masculino/feminino, podemos pensar e concordar que o conceito de heteronormatividade mesmo quando desconstruído, sustenta a dicotomia no gênero, para Monique Wittig (2019) são essas categorias que são responsáveis pela manutenção da heterossexualidade, para ela a lésbica encontra-se fora dessas categorias: "Lésbica é o único conceito que eu conheço que está fora das categorias de sexo (mulher e homem), porque o sujeito designado (lésbica) não é uma mulher, seja economicamente, politicamente ou ideologicamente." (WITTIG, 2019, p. 91).

É possível que a condição que Vivi reivindica esteja mais próxima de um posicionamento fora do sexo, algo que vai além da relação afetivossexual com Marcela, uma reinvindicação política e ideológica, onde o empoderamento esteja distante dos parâmetros patriarcais, colocando-se fora do espaço heterocentrado defendido por Wittig (2019). Pois ela não deseja o estereótipo da lésbica femme, tampouco performatiza o oposto do feminino e muitas vezes esperado pelo sujeito que pensa estar elogiando ao dizer "você não parece nem um pouco". A sua fala se aproxima de um posicionamento que coloca a lésbica a margem dessas relações heteronormativas e do poder patriarcal.

Mas, voltemos à resposta que, ainda, paira quase que etérea diante de todas as elucubrações que se desenvolveram na mente das personagens. A única possível conforme o pensamento de Vivi, pois na mente dela não havia "armários" uma vez que "era assumida, nunca tinha escondido o que sentia por Marcela [...]. Entretanto impossível negar o quanto tinha medo de se expor em público.” (ROIZ, 2017, p. 75). Mas o próprio pensamento dela demonstra que a "saída do armário" se dá em diferentes níveis sociais.

Neste momento a personagem Vivi repassa mentalmente todos os motivos que a impedem de revelar e demonstrar publicamente sua relação com Marcela e relembra todas as violências que soube pela mídia e por relatos de amigas que foram vitimas de agressões, temia por ela, temia pela mulher que amava. Pensava o quanto era difícil diante de inúmeras situações contrárias, cada nova situação vivenciada tendo que elaborar e reelaborar-se, conforme tão bem é dito por Sedgwick (2007): 
Cada encontro com uma nova turma de estudantes, para não falar de um novo chefe, assistente social, gerente de banco, senhorio, médico, constrói novos armários cujas leis características de ótica e física exigem, pelo menos da parte de pessoas gays, novos levantamentos, novos cálculos, novos esquemas e demandas de sigilo ou exposição. Mesmo uma pessoa gay assumida lida diariamente com interlocutores que ela não sabe se sabem ou não. (SEDGWICK, 2007, p. 22).

Manter-se no "armário" significa a proteção, a segurança: “[...] até entre pessoas mais assumidamente gays, há pouquíssimas que não estejam no armário com alguém que seja pessoal, econômica ou institucionalmente importante para elas [...]" (SEDGWICK, 2007, p. 22).

Para Marcela e Vivi, o sujeito talvez não represente importância pessoal, tampouco tenha alguma relação direta na vida delas, mas o que opera fortemente nessa situação é o poder simbólico que, nas sombras, emerge no espaço público colocando-as em evidência e que cobra uma postura na qual os esquemas de pensamento são incorporados, resultado das relações de poder e que colocam em oposição o masculino/feminino. Tornando essa "saída do armário" uma afronta às regras:

O armário gay não é uma característica apenas das vidas das pessoas gays. Mas para muitas delas, ainda é uma característica fundamental da vida social, e há poucas pessoas gays, por mais corajosas e sinceras que sejam de hábito, por mais afortunadas pelo apoio de suas comunidades imediatas, em cujas vidas que armário não seja ainda presença formadora. (SEDGWICK, 2007, p. 22).

Assim, percebe-se pela narração e fluxo do pensamento das personagens que manter-se no armário era sempre uma opção, mas também uma afronta, uma agressão a elas mesmas. Chegamos ao ápice da história e a impressão diante da narrativa é de que para protegerem-se, para não revelarem-se, para evitarem qualquer vexação pública o consentimento é certo e logo veremos, do local onde a narradora nos colocou três pessoas conversando alegremente e não teríamos qualquer alteração na estrutura e tampouco, perceberíamos o desenrolar daquele encontro que em nada abala a normalidade. Assim simples, como sempre foi.

O silêncio das duas foi tomado como consentimento, com um ar vitorioso repleto de certeza na imprescindibilidade de sua presença e confiança na própria capacidade de salvar a noite de uma, ou talvez com sorte, das duas mulheres solitárias [...]. (ROIZ, 2017, p. 75).

Mesmo não havendo por parte das duas mulheres nenhum incentivo, nenhum sinal, tampouco e provavelmente não tivessem nem notado a presença do sujeito até o momento em que ele as interpela, a segurança com que o indivíduo se coloca contrastando com o silêncio quase que constrangido das duas mulheres é legitimado por uma estrutura social onde o poder do masculino dita as regras do jogo social e se impõe frente a passividade do feminino.

Porém, o que segue não é nem perto o que o sujeito, que naquele momento já se aproximava puxando a cadeira, esperava. A frase dita quase que num momento de catarse, após 
todas as elucubrações de Vivi: “- Fique aí onde está” (ROIZ, 2017, p. 75).

Para elas a frase diz mais do que literalmente informa, é a afirmação de uma identidade de assumir-se fora de um contexto heteronormativo e mais ainda é informar que "não estão sozinhas" somente pelo fato de não haver o sujeito masculino e a frase que vem a seguir nos faz mudar o foco da nossa atenção para o sujeito que "surpreso" talvez por se achar imprescindível até então, talvez pelas mãos dadas que elas expõem, talvez pela ausência de sentido que ele vê na cena, talvez por, enfim, se dar conta de sua própria solidão.

“-Quem está sozinho é você, nós duas estamos juntas” (ROIZ, 2017, p. 76).

Este é o ponto alto e o derradeiro final feliz, pois ao não estarem sozinhas, assumem "[...] alto o suficiente para ser ouvida por todo o bar [...]" (ROIZ, 2017, p. 75) que habitam outro espaço na estrutura social. Assumindo a categoria de abjeção. Transgredindo a ordem e o destino fadado pelo sistema sexo - gênero - desejo.

\section{Considerações finais}

A opressão que as mulheres sofrem pelo fato de serem mulheres é, atualmente, colocada em debate em muitas dimensões do campo social. Na literatura, nosso campo de pesquisa e atuação, percebemos que o surgimento de escritoras feministas, com toda sua pluralidade, que trazem nas suas narrativas as vozes que foram silenciadas ou apagadas ao longo da história tem um protagonismo importantíssimo nas transformações e principalmente nas resistências necessárias nos dias atuais. $\mathrm{O}$ aumento da produção literária tanto quantitativamente quanto qualitativamente é significativo quando comparamos com dados do século XIX e XX, que apesar de termos uma grande produção de autoras mulheres, conforme a vasta pesquisa de Zahidé Muzart (2004) nos mostrou, foram silenciadas.

A significativa produção de literatura lésbica, aqui adjetivada em virtude de um posicionamento político e não de taxonomia, ainda circula às margens das grandes editoras nacionais, porém se faz presente em blogs, sites, grupo em redes sociais, editoras independentes e da mesma forma, ainda, é insipiente na academia que, ainda tem nos cânones a maioria de sua produção.

Ao analisarmos o conto "Duas mulheres sozinhas" de Diedra Roiz (2017), a partir das teóricas do feminismo, fomos além dos objetivos iniciais deste trabalho, pois no exercício de localizar os conceitos do corpus teórico escolhido, compreendemos que nossa própria análise, algumas vezes, está comprometida com as estruturas que fundamentam o sistema que criticamos, assim, o cuidado com o discurso que assumimos, muitas vezes, é mais fundamental do que o próprio lugar de chegada.

Diedra Roiz nos faz refletir sobre os lugares subalternos que a mulher ocupa na sociedade, sendo seu valor medido a partir dos vínculos com o homem. Se ela está sozinha, está pela metade. A produção literária de mulheres que trazem o protagonismo das mulheres em todas as suas multiplicidades e pluralidades tanto na representação quanto na representatividade é um caminho revolucionário. 


\section{Referências}

BUTLER, Judith. Problemas de gênero: feminismo e subversão da identidade. Trad. de Renato Aguiar. Rio de Janeiro: Civilização Brasileira, 2013a.

BUTLER, Judith. Corpos que pesam: Sobre os limites discursivos do sexo. In: LOURO, Guacira Lopes. O corpo educado: pedagogias da sexualidade. 3. ed. Belo Horizonte: Autêntica Editora, 2013b, p. 151-172.

DALCASTAGNÈ, Regina. Representações restritas: a mulher no romance brasileiro contemporâneo. In: DALCASTAGNÈ, Regina; LEAL, Virgínia Maria Vasconcelos (Orgs.). Deslocamentos de gênero na narrativa brasileira contemporânea. Vinhedo: Horizonte, 2010. p. $40-64$.

LAURETIS. Teresa de. A tecnologia de gênero. In: HOLLANDA, Heloisa Buarque de (Org.). Tendências e impasses: o feminismo como crítica cultural. Rio de Janeiro: Rocco, 1994, p. 206-242.

RICH, Adrienne. Heterossexualidade compulsória e existência lésbica. Bagoas: estudos gays: gêneros e sexualidades, Natal, v. 4, n. 5, p. 17-44, jan./jun. 2010.

ROIZ, Diedra. Duas mulheres sozinhas. In: NEVES, Manuela; ROIZ, Diedra (Orgs.). [in] contadas - Aquelas que não podem falar dizendo o que não deve ser dito. Franca: Editora Vira Letra, 2017, p. 73-76.

SANTOS. Claudiana Gois dos. A bruta flor do Querer: performance e heteronormatividade na representação da personagens lésbicas. 2018. Dissertação (Mestrado em Estudos Comparados de Literaturas de Língua Portuguesa) - Faculdade de Letras, Filosofia e Ciências Humanas da Universidade de São Paulo, Programa de Pós-Graduação em Estudos Comparados de Literaturas de Língua Portuguesa, Universidade de São Paulo, São Paulo, 2018.

SEDGWICK, Eve Kosofsky. A epistemologia do armário. Trad. de Plinio Dentzien. Cadernos Pagu, Campinas, n. 28, p. 19-54, jan./jun. 2007.

SPIVAK, Gayatri Chakravorty. Translator's Preface. In: DERRIDA, Jacques. Of Grammatology. Trand. de Gayatri Chakravorty Spivak. Baltimore: The Johns Hopkins University Press, 1998, p. ix- lxxxvii.

WITTIG, Monique. Não se nasce mulher. In: HOLLANDA, Heloisa Buarque de (Org.). Pensamento feminista: conceitos fundamentais. Rio de Janeiro. Bazar do tempo, 2019, p. 8292.

MUZART, Zahidé Lupinacci (Org.). Escritoras Brasileiras do Século XIX. Antologia. Florianópolis: Editora Mulheres; Santa Cruz do Sul: EDUNISC, 2004. 2. v.

\section{NOTAS DE AUTORIA}

Eliane Santos da Silva (elianesilva94@gmail.com) é bacharel em Ciências Sociais pela Universidade Federal de Santa Catarina (2003). Licenciada em Pedagogia pela Universidade do Estado de Santa Catarina (1015) Especialista em Educação Ambiental/Modalidade 
magistério superior pela Unidavi. Especialista em Gestão de Recursos Hídricos em áreas urbanas pela UFSC. Mestranda no Programa de Pós-Graduação em Literatura da UFSC.

Rosana Cássia dos Santos (rosanack@yahoo.com.br) é Professora Associada da Universidade Federal de Santa Catarina, na área de Literatura. Coordenadora do GT da Anpoll A Mulher na Literatura, no biênio 2014-2016. Integrante do Grupo de Pesquisa do Instituto de Estudos de Gênero - IEG/UFSC. Integrante da Editoria de Artigos da Revista Estudos Feministas - REF. Coordenadora do Núcleo Literatual. Bolsista de Produtividade em Pesquisa do CNPq - Nível 2.

\section{Como citar esse artigo de acordo com as normas da revista}

SILVA, Eliane Santos da; SANTOS, Rosana Cássia. "Vocês estão sozinhas?" A resposta está na pergunta. Anuário de Literatura, Florianópolis, v. 25, n. 1, p. 77-86, 2020.

\section{Contribuição de autoria}

Eliane Santos da Silva: Concepção, coleta de dados e análise de dados, elaboração do manuscrito, redação, discussão de resultados.

Rosana Cassia dos Santos: Auxílio na concepção, coleta de dados e análise de dados, discussão de resultados.

\section{Financiamento}

O presente trabalho foi realizado com apoio da Coordenação de Aperfeiçoamento de Pessoal de Nível Superior - Brasil (CAPES) - Código de Financiamento 001.

\section{Consentimento de uso de imagem}

Não se aplica.

Aprovação de comitê de ética em pesquisa

Não se aplica.

\section{Licença de uso}

Este artigo está licenciado sob a Licença Creative Commons CC-BY. Com essa licença você pode compartilhar, adaptar, criar para qualquer fim, desde que atribua a autoria da obra.

\section{Histórico}

Recebido em: 25/11/2020

Revisões requeridas em: 26/02/2020

Aprovado em: 10/03/2020

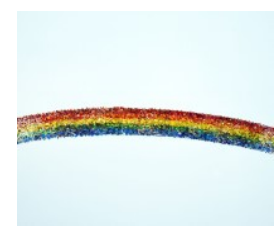

